This article considers to understand the work of art for a Nietzchiana's perspective. The objective is to come back the look toward the visual arts in which the body is the main one half of artistic expression and the focus of the tragic experience. This assay searchs a foundation theoretical in the apollonian-dionysiac relation like a key to transfiguration poetical. The words subscribed in this article point the changes of poetical attitude of Fernanda Magalhães after its confrontation with the tragic experience that it became possible to reach new horizon where the art always is the basic tool of the life and the soul.

Key-words: Body, Fernanda Magalhães, Tragic experience. 


\section{O Corpo de Fernanda Magalhães perante a experiência trágica}

Fábio Luiz Oliveira

GATTI

O presente artigo propõe-se a compreender a obra de arte por uma perspectiva Nietzschiana voltando-se os olhares para as artes visuais, onde o corpo é o principal meio de expressão artística e foco da experiência trágica, buscando-se neste ensaio um alicerce teórico na relação apolíneo-dionisíaca como chave para a transfiguração poética. As palavras aqui subscritas demonstram a mudança de atitude poética de Fernanda Magalhães após o seu enfrentamento com a experiência trágica pela qual foi possível alcançar novos horizontes onde a arte sempre é a ferramenta fundamental da vida e da alma.

Palavras-Chave: Corpo, Fernanda Magalhães, Experiência trágica. 


\section{Introdução}

Na perspectiva das modificações que o corpo enfrenta no campo das manifestações artísticas, interessa-nos, neste artigo, estudar o trabalho produzido por Fernanda Magalhães (1962-) e pontuar a mudança ocorrida em sua poética a partir da experiência trágica. Fernanda Magalhães é artista e fotógrafa, atua no campo das artes visuais desde os anos de 1980. Seu trabaIho é uma imersão nas questões relacionadas ao corpo em nossa sociedade contemporânea. O corpo é a problemática oficial de sua poética. A artista, em tais discussões, extrapola o limite da carne e faz seu corpo transcender a uma supradimensão que só pode ser vivenciada pela experiência estética.

Nos anos 1990, sua poética leva-nos a dimensões críticas acerca das normas estabelecidas pela sociedade e a relação com o seu próprio corpo, enfocando a questão do preconceito. Declara, então, a libertação de seu corpo, fazendo dele a sua voz perante a sociedade. Após seu enfrentamento com o pessimismo de Sileno ${ }^{1}$, pela possibilidade de esvaziamento de vida, numa perspectiva de proximidade com a morte, ocorre a filotransmutao ${ }^{2}$ de sua poética.

As abordagens ocorridas nos anos 1990 irão perdurar por toda sua produção, o que se modifica é apenas o foco estabelecido pela artista. O corpo da mulher gorda continua a penetrar a obra, mas com o enfrentamento da experiência trágica, ele deixa de ser a principal instância de seus questionamentos. Os padrões da sociedade continuam a ser indagados em seu trabalho, mas com um novo enfoque, pois falam do corpo como carne, como humano, e não mais como gordura. O corpo da artista, que sofria a opressão social devido à gordura, a partir de 2003 é oprimido pela doença que encerra uma percepção acerca da finitude por meio de uma experiência trágica que marcará e modificará o desenvolvimento de sua poética.

As ciências e os mitos demonstram-nos que a morte é nossa companheira diária, estando conosco desde nossa concepção no ventre materno e, portanto, a partir daí começamos nossa peregrinação, infindável, para o abismo. Durante esse percurso, deparamo-nos com a vida. Esta, ou melhor, a possibilidade de se estar vivo de modo ativo é a grande geradora de nossas 
pulsões na luta sem fim pela existência. A dicotomia vida-morte, nosso antagonismo cotidiano, é o fator propulsor que nos conduz a uma infinidade de experimentações, ampliando a esfera de nossas experiências sinestésicas.

O fato de estarmos mergulhados em vida e, portanto, na própria morte, governa-nos diariamente, declara-nos a dimensão única da vida: a morte. Apesar de sabermos que esta nos acompanha, tentamos nos livrar dela e de sua possibilidade, afastando sua concretude inegável do nosso dia a dia.

Os trabalhos de Magalhães conectam-se através da utilização do corpo e das referências autobiográficas, mas principalmente por estarem, de alguma forma, ligados a idéia de passagem. Em A Representação da Mulher Gorda Nua na Fotografia (1993) e em Classificaes Cientficas da Obesidade (1998) o corpo gordo é tabu, transgressor, sempre estará fadado a transformar-se, nunca poderá ser gordo, mas sim estar gordo e, por isso, ser passível de modificação. Já os trabalhos realizados a partir de 2003, quando do enfrentamento da experiência trágica, intermediária entre a vida e a morte, que traduzem a confrontação com as agonias da vida, o temor da morte, a transgressão e a proibição que se repetem surgem através da doença, fatores presentes nas obras S.O.S, Corpo-Reconstruo AoRitualPerformance, Caderno de Anotaes, Ibum Cicatriz e Fotografias Manipuladas.

\section{O corpo e a poética em seu encontro com a possibilidade da morte}

Sabemos que a morte é nossa companheira diária, pois de acordo com Alves (1998, p.12) "a morte não é algo que nos espera no fim. É companheira silenciosa [...]". Sabemos que a vida não existiria sem a morte e vice-versa. Notamos, também, que um dia, em determinado horário e local, a morte virá ao nosso encontro. Será que ele é doloroso? Será que a morte é boa ou ruim? Será que existe uma resposta para a morte? Acreditamos que a reposta para a morte está na vida. Por isso, a dicotomia vida-morte faz delas amigas inseparáveis. 
Nem sempre a morte foi tão traumatizante. Houve um tempo em que a morte era natural, sabia-se que ela tinha um significado, que a partir daquele momento algo se modificaria, e "frustar-se ao aviso da morte era expor-se ao ridículo" e, além disso, a morte era tida como costumeira, seu acontecimento não era estranho e ela pairava sobre a vida de todos com benevolência, "era comum, normal, não se apoderava, traiçoeira, da pessoa[...]" (ARIES, 1989, p.11 e 07 respectivamente).

Edgard Morin (1997) em seu ensaio intitulado O homem e a morte esclarece inúmeros fatores relativos à morte e sua relação com os animais. Incluímo-nos no reino animal, mas dele nos diferenciamos pela racionalidade, porém esta capacidade não nos livra da mortalidade. Para o autor existem três tipos de morte: "a morte-agressão, a morte-perigo, a morte-inimiga". A poética de Fernanda Magalhães transforma-se justamente pelo encontro com estes três tipos.

Estar diante da morte, reconhecer a sua existência e torná-la comum foi, até o século XVIII, fato celebrado. Após algum tempo, por meio das Ciências, a morte passou a denotar outras características. Começou, assim, a nova visão da morte no Ocidente. De companheira, passou a ser inimiga, negada, abolida. Nem mesmo se pode falar sobre ela. "Tornou-se um tabu, uma coisa inominável e, como antigamente o sexo, não se deve falar nela em público" (ARIÈS, 1989, p.161).

É a individualidade humana, que se mostra lúcida diante de sua morte, que fica traumaticamente afetada por ela, que tenta negá-la, elaborando o mito da imortalidade. [...] portanto, é porque seu saber da morte é exterior, aprendido, não inato que o homem é sempre surpreendido pela morte. A morte [...] aparece como um acidente, um castigo, um erro, uma irrealidade (MORIN, 1997, p.61).

Tal mudança de comportamento torna a morte o pior dos fatores do estar vivo. O horror de se deparar com ela causa pânico, é assombroso. Baudrillard (DANTAS, 2003, p.65) leva-nos a refletir sobre o aspecto "anormal" do estar morto em nossa sociedade; falando que tal condição não é aceita e que 
"isto é novidade", o que leva a morte a tornar-se uma "anomalia impensável, um desvio incurável".

Esse é o desvio evitado por todos nós. O aproximar-se da morte é uma possibilidade obrigatoriamente afastada de nosso cotidiano, eliminada de nossas vidas e, portanto, de nosso vocabulário. Estar diante dela é sempre uma possibilidade muito remota, da qual não temos conhecimento e com a qual não há comunhão como nas sociedades antigas. Natural, atualmente, é permanecer vivo, jovem, e não morto.

Nesse contexto, transformam-se os pensamentos ao redor das ciências médicas, os quais determinam o que seria patológico e o que seria normal. Cada sociedade, em sua época e à sua maneira, vivenciou certos tipos de experiências sociais que estabeleceram padrões a serem seguidos pelas pessoas ${ }^{3}$. Como determinar o que é normal, visto que tal conceito está ligado intimamente, como demonstra Canguilhen (1995, p.209), à idéia do "protótipo escolar e o estado de saúde orgânica"? Nessa indagação encontram-se fundadas as relações da sociedade com a questão da gordura, tão discutida no trabalho de Magalhães.

Então, como fazer para nos livrar do monstro criado por nós mesmos com nossas normas e padrões? Este questionamento não é o objeto das reflexões que fazem parte deste estudo, entretanto, vale salientar que, se possuímos atualmente estereótipos, sejam eles de qualquer ordem, estes são fruto de nossa sociedade com suas pesquisas infindáveis e buscas desmedidas por respostas e soluções que acabam por tornar o individuo uma marionete que vive a representação das idéias ditadas por poucos, pois a massa absorve as informações e as doutrinas como se fossem verdades cientficas, portanto, inquestionáveis.

Ressaltamos aqui, como pondera Lyotard (1986, p.12 e 29), que "o saber científico não é todo saber" e que "a ciência seria apenas um subconjunto do conhecimento". Desse modo, por que aceitamos tão aberta e prontamente o que nos é apresentado? Por que o corpo gordo deve ser interditado como a própria morte o foi em nossa sociedade? O que torna o corpo gordo tão monstruoso que ele, assim como a morte, não deva existir? Quem torna o corpo gordo o transgressor? Como se 
estabeleceram tais parâmetros? É difícil, atualmente, aceitar a ciência médica como onipotente ou detentora da verdade absoluta, mesmo sendo esta a imagem que ela pretende nos fazer acreditar, pois a sanidade do corpo, ou melhor, do homem, segundo Canguilhen (1995, p.261), não é pura sanidade, é a expressão do "equilíbrio conquistado a custa de rupturas incoativas", sendo que a "doença é um dos elementos construtivos da saúde".

Tanto a morte como a gordura são considerados estados doentios, pois não pertencem mais à ordem do natural e sim, da patologia. Ser gordo(a), assim como morrer, é cada vez mais expelido de nosso vocabulário e, principalmente, de nosso dia-a-dia. Entretanto, discutir a doença é necessário, pois é por meio dela que a morte se aproxima mais claramente. A doença que encontra o homem e o aproxima de sua finitude, o torna vulnerável, constituindo sua própria vitalidade. É nessa esfera que Fernanda Magalhães aproxima-se de sua experiência com a morte. Quando estabelecido o diagnóstico de um câncer, esse laço de aproximação se constrói e se torna o responsável pela sua ressurreição.

Em resposta a tal diagnóstico, Magalhães coloca-se em um ritual de retorno a si, numa busca diária, pois ritualizar é repetir ordenadamente. Esse rito é inconsciente na artista, ela adentra em suas entranhas, vasculha suas vísceras orgânicas e sentimentais, experimenta, pela dor, a potência da vida. Estabelece, assim, o diálogo de seu corpo com a imperfeição de sua matéria ${ }^{4}$, respondendo a isso, com o abalo de seu bem-estar, "simples consciência de viver e só seu impedimento suscita a força de resistência" (KANT CANGUILHEN, 1995, p.206). Fernanda encontra a afirmação da vida, enfrentando sua morte, por meio da arte.

A doença, em Fernanda Magalhães, é a grande responsável pelas muitas mudanças de sua atitude como artista. A possibilidade de morrer a qualquer instante era extremamente nociva e amedrontadora, mas, como resposta a essa violência, a artista age tão violentamente quanto sua doença, numa luta constante pela efetivação de sua existência contra a morte de seu corpo, ou melhor, de parte do seu corpo, pois seu útero foi 
retirado devido ao câncer. Ela descobre a transcendência pela arte e propõe uma filotransmutao de sua obra. Contudo, "o risco da morte implica sempre uma participação do indivíduo, na qual o indivíduo pode dominar seu horror da morte" (MORIN, 1997, p.75). É justamente o que Fernanda faz através da criação artística.

A palavra filotransmutao foi criada a partir de raízes etimológicas que compõem nossos vocábulos, com o fim único de abarcar a transformação sofrida pela poética de Fernanda Magalhães, estudada e discutida no presente texto, com intuito de englobar todas as significações necessárias das quais o trabalho está carregado.

Sendo assim, escolhemos filo por significar amor, desejo. Trans por exprimir a idéia de estar "além de". Mut por denotar alteração, modificação. Ao porque se trata de uma atitude da artista perante a perspectiva da morte devido ao câncer diagnosticado em 2003. Essa ação tem algo de sublime que corresponde ao caráter de exaltação, pois é um trabalho que exalta a vida em relação à morte; luta pela afirmação da vida tornando-se mais intenso.

Filotransmutao quer dizer: ação, por meio da experiência estética, do fazer artístico, que propõe uma supramodificação poética, posicionando o trabalho para além das aparências, numa relação de força incomparável entre a afirmação da vida e da morte, abrindo um novo trilhar na poética da artista, quando se colocou em cheque o momento anterior e o posterior ao enfrentamento com a morte por intermédio da doença. Fato responsável pela aproximação da artista da lucidez de sua finitude e de sua voraz intensidade em afirmar sua própria vida por meio da arte.

Mesmo sabendo da existência da expressão agenciamentos do corpo, utilizada por Melim (2003), para representar as atitudes que colocam o corpo perante a arte, utilizando-o como construtor e constituinte de um trabalho, como suporte, como objeto presente ou ausente, ou como simples idéia de sua representação simbólica, tal expressão não seria capaz de exprimir a verdadeira face do acontecimento em Fernanda Magalhães. Por este motivo, o termo criado será utilizado freqüentemente para conseguir 
revelar o caráter implacável da filotransmutao da poética de Fernanda Magalhães, de quando surge a notícia sobre a doença.

Filotransmutar-se só seria possível pela experiência trágica. Pela conciliação dolorida entre Apolo e Dionísio ${ }^{5}$. Pela percepção do pessimismo de Sileno, aceitação dos Véus de Maia e do êxtase dionisíaco.

A tragédia, por resgatar ainda que esteticamente o dionisíaco, tem de transitar, em algum momento, na obscuridão, no invisível, naquilo que é olhar em transe, uma espécie de olhar "de dentro", sem distância entre o sujeito e aquilo que ele contempla (MEICHES, 2000, p.141).

A doença que traz a premissa da morte, que remete a um estágio intermediário, que prescreve um caminho tido como certo, um caminho para o abismo, torna-se, a partir da experiência trágica, a força que conduz Fernanda à experiência estética, e esta à possibilidade de permanência, de afirmação da vida.

De fato a doença apaga, mas sublinha, abole de um alado, mas é para exaltar de outro; a essência da doença não está somente no vazio criado, mas também na plenitude positiva das atividades de substituição que vem preenchê-lo. [...] Assim como o medo é reação ao perigo exterior, a angústia é a dimensão afetiva desta contradição interna. Desorganização total da vida afetiva, ela é a expressão maior de ambivalência, a forma na qual se termina, porque é a experiência vertiginosa da contradição simultânea, à prova de um mesmo desejo de vida e morte, amor e ódio[...] (FOUCAULT, 1994, p.24 e 50).

O posicionamento da artista, utilizando seu corpo, torna "sua forma, sua postura, sua disposição, suas manifestações, suas sensações" capazes de emitirem "significados, os quais são compreendidos através de uma imagem construída" (VICTORA, 2001, p.75). Na verdade, através de muitas imagens construídas pela artista. Imagens que a priori são fotográficas, porém, não se restringem ao aparato fotográfico, extrapolam os limites do papel fotográfico e alçam vôo para diferentes experimentações, pela arte.

No sentido de reconhecer-se a si mesma, Magalhães torna 
sua própria morte um espelho de sua vida; descobre que a "sua morte não é menos surpreendente do que sua vida" (AIRÈS, 1989, p.10) e faz dela o pivô de sua experiência trágica. Assim como a gordura, a morte também é considerada transgressão e é pelo prenúncio de uma morte que a artista resolve não calar-se, não escamoteando a possibilidade da ausência da vida, mas lutando através da arte pela transcendência de si mesma. Fernanda Magalhães faz de si mesma um instrumento de reconstrução contínua, validando sua presença no mundo pelo seu trabalho.

Para toda essa reconstrução e finalmente atingir aquilo que chamo de filotransmutao, Magalhães vivenciou, durante todo o período intermediário entre vida e morte, causado pela doença, a experiência trágica.

Essa experiência trágica foi esclarecida por Nietzsche (s/d) através da batalha entre o que é aparência (apolíneo) e o que é essência (dionisíaco). A arte apolínea é uma resposta ao deus Sileno, a qual busca um processo de individuação, faz apologia ao real, portanto dissimula a realidade, isto é, utiliza o véu de Maia que cobre, encoberta a realidade. A arte dionisíaca, por sua vez, é uma pulsão total entre a aparência e a essência, uma permanente discussão de equilíbrio entre tais partes, impelindo o sujeito a romper com a individualidade e retornar à unificação entre o Ser e a Natureza. Faz do encontro com a dor um retorno ao êxtase e, por fim, após sua embriaguez total, depara-se novamente com o pessimismo de Sileno, com a noção de sua finitude. Portanto, para Nietzsche, a salvação está em conciliar esses dois pólos: apolíneo e dionisíaco e essa conciliação ocorre através da criação artística que é capaz de transformar em aparência a dolorida realidade.

No entanto, encontrar tal ponto de equilíbrio é uma atividade fatigante, pois os dois pólos se conjugam em separado e, portanto, tornam-se independentes um do outro, ocorrendo cada qual ao seu devido tempo.

Não podemos pensar que o processo do trágico começa somente em Dionísio. O trágico inicia-se no momento em que se estabelece o processo de individuação proposto pela arte apolínea. A partir de então, os seus desdobramentos ocorrem: 
O homem tem de enfrentar o doloroso processo de individuação construindo para si próprio uma identidade que o proteja o máximo possível da devastação pelo conhecimento da verdade da vida como ela é...

Esse jogo estético entre [...] beleza apolínea e a embriaguez dionisíaca $[. .$.$] tornou-se emblemático de uma luta travada na$ cultura entre o pessimismo e a arte, entre os riscos da negação da vida e a ilusão da arte; uma luta na qual vence, a vida, ao lograr, pela arte, recuperar para si o homem (RODRIGUES, 1998, p.30 e 56).

Na busca pela superação da experiência trágica, estabelece-se, no trabalho de Magalhães, uma característica antes não encontrada, isto é, o caráter rizomático inicia sua aparição comprovando que

não somos mais os mesmos. Cada um reconhecerá os seus. Fomos ajudados, asperados, multiplicados. [...] em qualquer coisa, há linhas de articulação ou segmentaridade, estratos, territorialidades, mas também linhas de fuga, movimento de desterritorialização e desestratificação. (DELEUZE e GUATTARI, 1995. p.11).

Notamos que a artista, ao se conectar com o rizoma, produz um movimento contínuo de desterritorialização - característica de quem se conecta a outros elementos, modificando-se - saindo de suas ações performativas e encontrando, no outro, um substrato de significância, extrapolando os limites do seu corpo, enxergando a importância do corpo do outro, da vida do outro e, portanto, também, da morte do outro como espeIho de si mesma em seu processo de filotransmutao.

Sabendo que "ser rizomorfo é produzir hastes e filamentos [...] que se conectam [...] podendo fazê-las servir a novos e estranhos usos" (ibidem, 1995, p.25), é possível verificar, na obra da artista, que seu corpo criou as hastes e os filamentos capazes de tangenciar o seu corpo numa ação interconectada com outros corpos, em outros lugares, em outras esferas da essência humana, encontrando a única possibilidade de vida que é a arte (MACHADO, 1999, p.39).

A dor causada pela consciência da morte despertada pela doença engendra o rizoma. Este tem como característica estar 
no meio, entre as coisas, e estabelece uma característica de continuidade infinita, estando sempre em transformação e ramificação.

Fernanda Magalhães reconhece a condição trágica da vida. Extrai dela a sabedoria de notar sua dor, detectar o lado horripilante da imanente escuridão que se faz presente, mas, no entanto, enxerga que, mesmo na dor, não existe porque fugir, não se faz necessário eliminá-la, mas sim criar uma potência de afirmação através da arte.

Se a arte é grande estimulante da vida, isto é, se cria uma superabundância de forças e um sentimento de prazer para com a existência é porque é uma aceitação total da vida, sem instituir valores superiores, [...] é porque valoriza a vida integralmente, é porque é um sem fim triunfante mesmo ao que nela existe de terrível, problemático e pavoroso (MACHADO, 1999, p.107).

A afirmação pela vida conecta-se com a necessidade de se possuir uma memória. Uma memória que pode ser deixada para os outros, que pode ser vivida por si mesmo, que pode ser produzida e ramificada. Memória que pode ser tida como atestado de existência. Toda força de Magalhães, toda a Vontade e desejo de continuar, pela arte, a sua vida, o seu ciclo ainda incompleto, faz de seu trabalho uma obra ímpar. Sua produção aumentou significativamente após o recebimento da notícia da doença, o que pode ser comprovado pelo número de séries, trabalhos e/ou projetos realizados a partir de 2003.

Ela não só deseja a afirmação da vida, como penetra profundamente nesse jogo dialético do trágico; lutando pela vida contra a morte ou pela morte como afirmação de vida, consegue chegar onde mais ansiava: no dia seguinte ${ }^{6}$.

Mesmo tendo sua poética filotransmutada, Fernanda MagaIhães continua com a temática do auto-retrato e em todas as suas produções ocupa-se em deflagrar o seu eu. Em A Representao da Mulher Gorda Nua na Fotografia (Figura 1 e 2) e em Classificaes Cientficas da Obesidade (Figura 3), a artista trabaIha em conjunto com outras pessoas, entrando em contato com outro corpo; é sempre um corpo próximo, um corpo-amigo, um corpo-conforto, repleto de afetos e similitudes; agora, com a 
filotransmutao, o corpo encontrado por Magalhães em seu trabalho é desconhecido. A artista sabe que este corpo desconhecido, a partir de agora, fez parte dela, integra-a a uma supradimensão que se tornou essencial em sua produção pela visita inesperada do trágico.

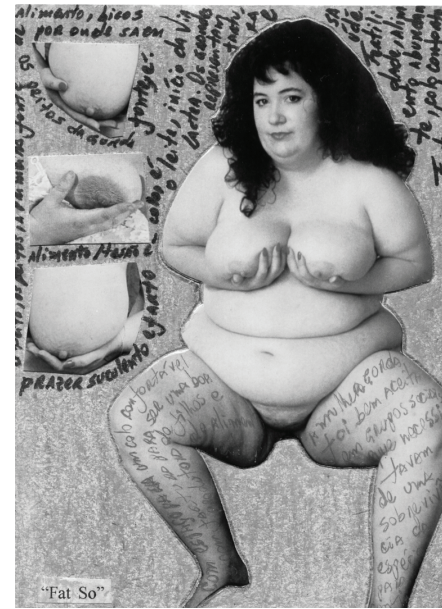

Figura 1 - Gorda 12 Fonte: Arquivo Fernanda Magalhães (2004-2006). Nardo Germano.

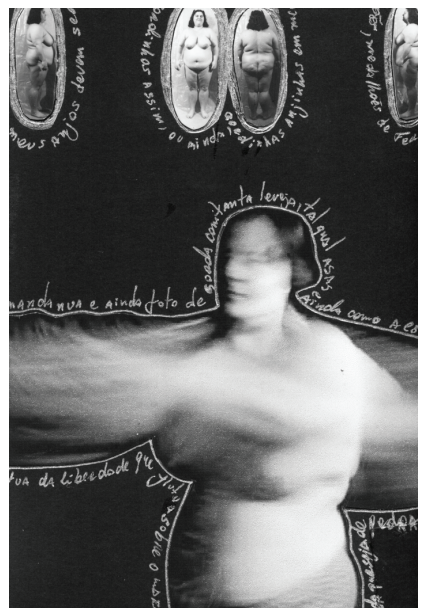

Figura 2 - Gorda 26

Fonte: Arquivo Fernanda.

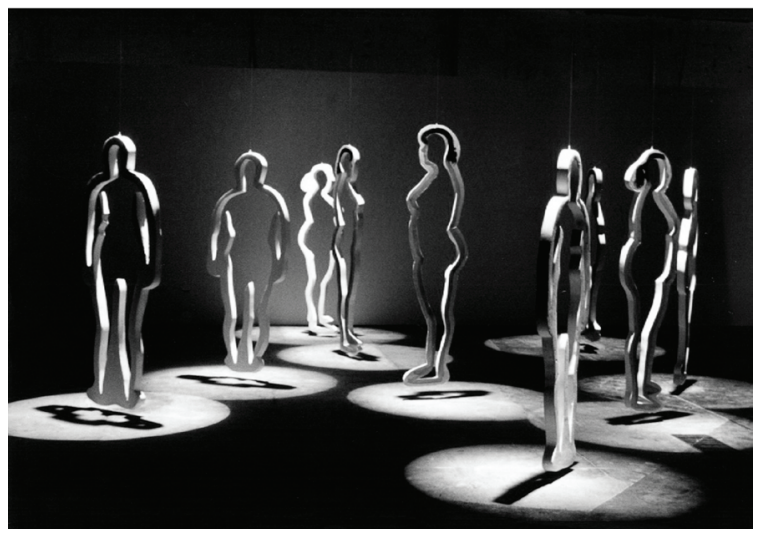

Figura 3 - Classificações Científicas da Obesidade Fonte: Arquivo Fernanda Magalhães. 
S.O.S, Corpo Re-Cosntruo Ao Ritual Performance, Caderno de Anotaes, Ibum Cicatriz e Fotografias Manipuladas são os trabalhos abordados nesse artigo, assim como as referências que demonstram as modificações poéticas do trabalho de Fernanda Magalhães denotando sua filotransmutao.

Em todos esses trabalhos, a experiência trágica se fez incisiva. As memórias que Fernanda Magalhães procura deixar ficam claras em todos os projetos. Memórias impressas como digitais de um indivíduo, provas de uma existência singular, são expressas através da fotografia em Corpo Re-Construo Ao Ritual Performance. Este trabalho surge em 2003 e pretende reconstruir a própria artista com a ajuda do Outro. Com o toque, a experiência e a doação do Outro. Essas ações são realizadas nos mais diferentes locais e até mesmo no atelier da artista, contudo resultam sempre na criação de lençóis com as impressões desses corpos. Corpos que se reconstroem pelo fragmento de outros corpos.

Assim, no meio do caos absoluto, no fundo da dor, [...] e na entrega absoluta deste corpo em convulsão, neste momento de tensão, como possibilidade de sobrevivência[...] o trabalho se constitui a partir de uma performance em grupo, de uma rede que tece um momento performático, composto de diversas ações que imprimem marcas, rastros e registros de passagem, como uma metáfora da vida (MAGALHÃES, 2006, p.82-83).

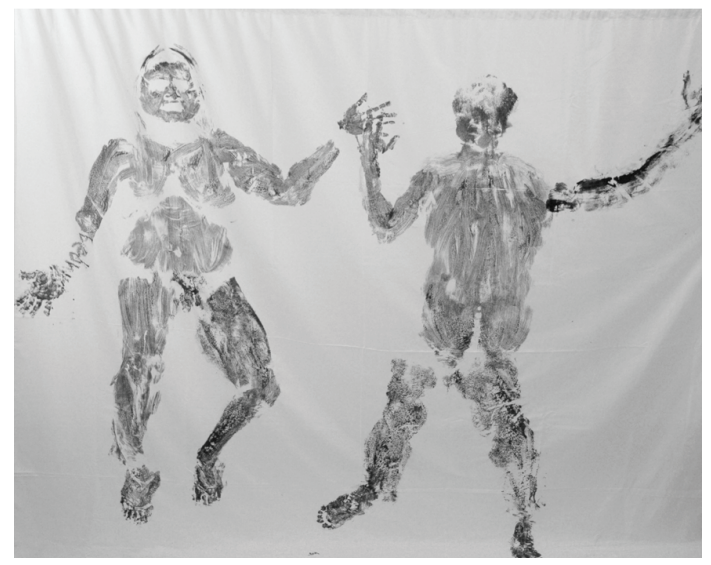

Figura 4 - Corpo Re-Construção - AçãoRitualPerformance Fonte: Arquivo Fernanda Magalhães. 


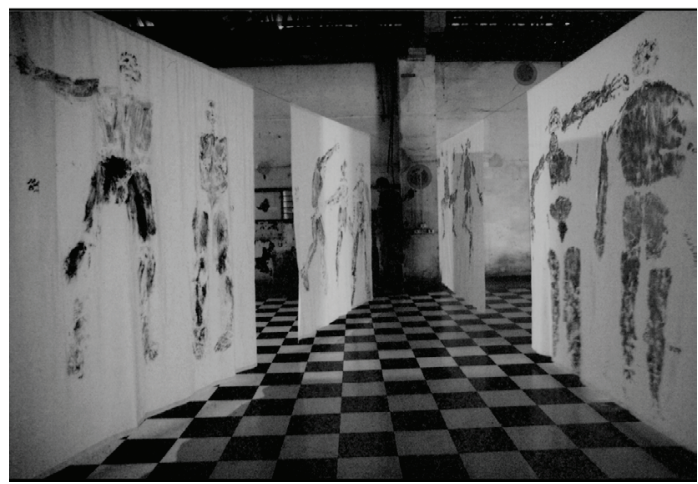

Figura 5 - Corpo Re-Construção - AçãoRitualPerformance Fonte: Arquivo Fernanda Magalhães.

Uma vida, a partir de agora, filotransmutada pela arte. Uma arte que afirma a vida pela experiência trágica. Um caos capaz de reconstruir um corpo esfacelado, mutilado, diante da constante percepção da sua finitude. Um corpo que absorve Sileno e o encobre com os véus de Maia e com a embriaguez de Dionísio e faz a poética da artista entrar em filotransmutao.

Um pedido de socorro que corre pelas mais diferentes águas, em ações rizomáticas, esse é o projeto S.O.S.. Fernanda elabora uma carta na qual pede ajuda. Ela pede uma imagem, um áudio, um vídeo, um registro de qualquer ordem. Solicita que esse registro seja enviado para uma caixa postal especificada na carta. Novamente, a necessidade do Outro se faz presente. Após a confecção das cartas - vale lembrar que esse trabalho ainda está em construção - a artista as coloca dentro de garrafas dos mais variados tamanhos, que podem ser de vidro, plástico ou outro material que seja transparente e faz o que chama de derramamento,pois, ao realizar sua primeira ação, está sob efeito de dores constantes, seguidas de uma hemorragia; isso leva a artista a nomear dessa forma. Um lançamento de si mesma em diferentes águas. Tais derramamentos são realizados por diferentes pessoas. Num primeiro ato, Magalhães concede as garrafas finalizadas com as cartas para os amigos próximos e, depois, a pessoas que não conhece, quando as envia para exposição na galeria da UNICAMP (GATTI, 2006a). Todas essas pessoas, amigos próximos ou não, 
lançam suas garrafas em diferentes águas e, assim, o trabalho atinge a dimensão da alteridade pela necessidade da artista em transcender-se: um corpo que derrama seus pedaços mundo afora pela presença e doação do outro; um corpo mutilado que pede ajuda e pedaços dos outros, pois precisa destes para que, diante de sua mutilação, diante do trágico, realize um movimento de retomada da vida, de filotransmutao de sua poética e de si mesma.

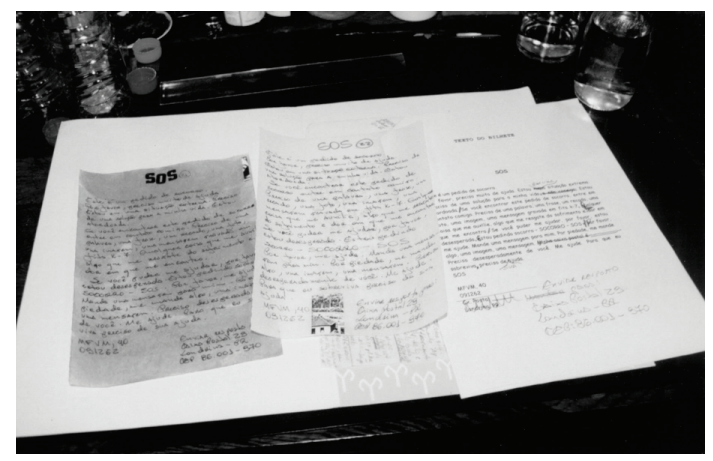

Figura 6 - Projeto S.O.S - detalhe dos materiais Fonte: Arquivo Fernanda Magalhães.

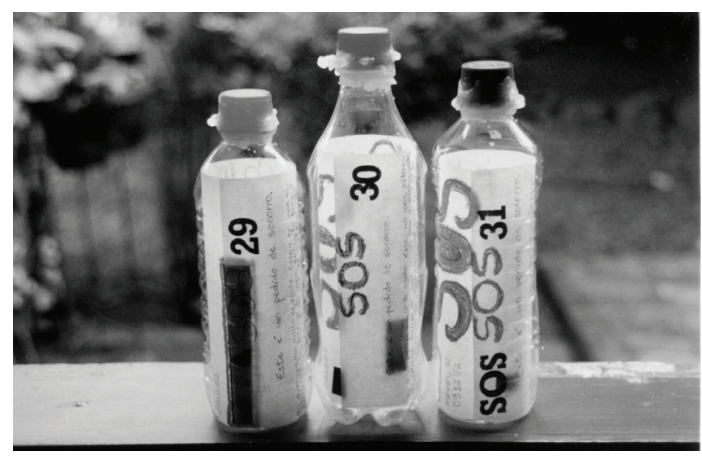

Figura 7 - Projeto S.O.S - detalhe garrafas que foram lançadas. Fonte: Arquivo Fernanda Magalhães.

Anotações diárias, um caderno de pensamentos, ações, referências, questionamentos, inquietudes; um caderno de celebração do dia seguinte. Um álbum que não tem fotos de famí- 
lia, que não tem festas de aniversário, um álbum que escandaliza o drama, que escancara o sangue, que grita pela marca da cicatriz de um corpo modificado pela tragédia. Uma passagem de vida que alcançou o seu futuro próximo, que chegou ao dia seguinte e, por isso, deixa a dor na marca da ausência de seu corpo, a ausência que poderia ter ocorrido, ausência que ocorre no processo de intermezzo, de estar no meio, em trânsito, em modificação, que passa pelo vazio e se completa no cheio. Cheio de vida, cheio de significações, cheio de mutabilidade, cheio do Outro e, portanto, filotransmutado.

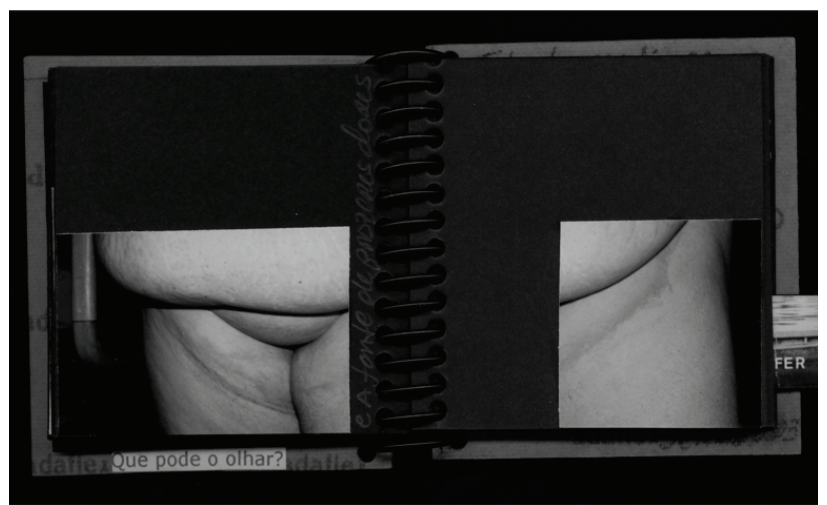

Figura 8 - Álbum Cicatriz pg.18

Fonte: Arquivo Fernanda Magalhães.

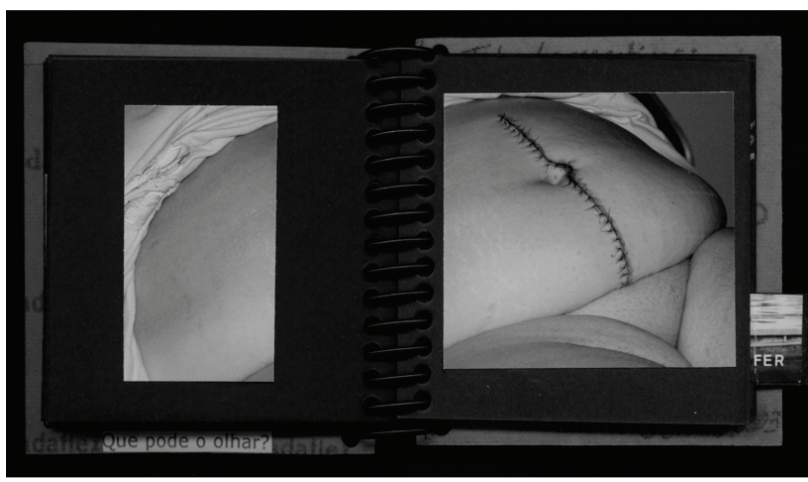

Figura 9 - Álbum Cicatriz pg.22

Fonte: Arquivo Fernanda Magalhães. 


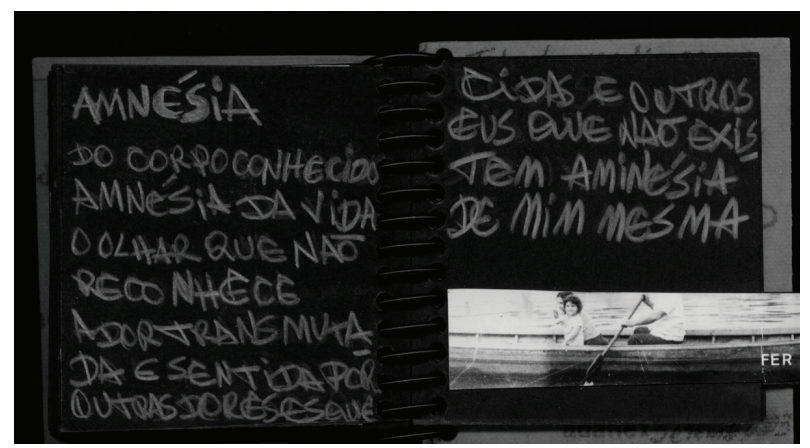

Figura 10 - Álbum Cicatriz pg.30

Fonte: Arquivo Fernanda Magalhães.

Deve-se esclarecer que o trágico em questão segue o pensamento de Nietzsche que diz: "o trágico aqui pertence a uma categoria que não somente a do $\sum$ belo; ele participa de um impulso que se aproxima o máximo de um estado de embriaguez" (NIETZCHE apud MEICHES, 2000, p.20).

Essa embriaguez a que Nietzsche se refere está presente na entidade do Deus Dionísio que proporciona um estado de êxtase, de sublimação da realidade. A arte dionisíaca procura afirmar um "eterno prazer da existência, mesmo quando seu olhar penetra os horrores da vida, esse prazer não pode ser buscado nas aparências, mas sim por detrás delas" (RODRIGUES, 1998, p.52), sem, é claro, deixar de olhar para tais aparências que são características, no dizer de Nietzsche, da arte apolínea, que "é o elogio à aparência [...] uma apologia da aparência como necessária não apenas à manutenção, mas à intensificação da vida" (MACHADO, 1999, p.20), por isso, é possível

através da arte $[. .$.$] enfrentar os perigos que o pessimismo re-$ presentaria para os homens de excessiva sensibilidade ao sofrimento seria como resgatar aquele ensinamento de como salvar o homem de ser paralisado por uma negação da vontade e do querer, fazendo-o acreditar na indestrutibilidade da vida; e, sobretudo, com isso, revelar a arte como o mais importante e necessário complemento metafísico da vida (RODRIGUES, 1998, p.58). 
A fotografia é o meio que Fernanda utiliza para construção de sua poética. Para a ar beloni cacique braga tista, tudo fotografia conforme relata na entrevista (GATTI, 2006b). Ela se utiliza dessa ferramenta como expressão e apresentação de seu trabalho, mas não é "pura apresentação, [...] define a humanidade sob a ótica da dor imposta por sua vulnerabilidade essencial face à morte" (LEENHART apud FRAIZE-PRERIRA, 2005. p.117).

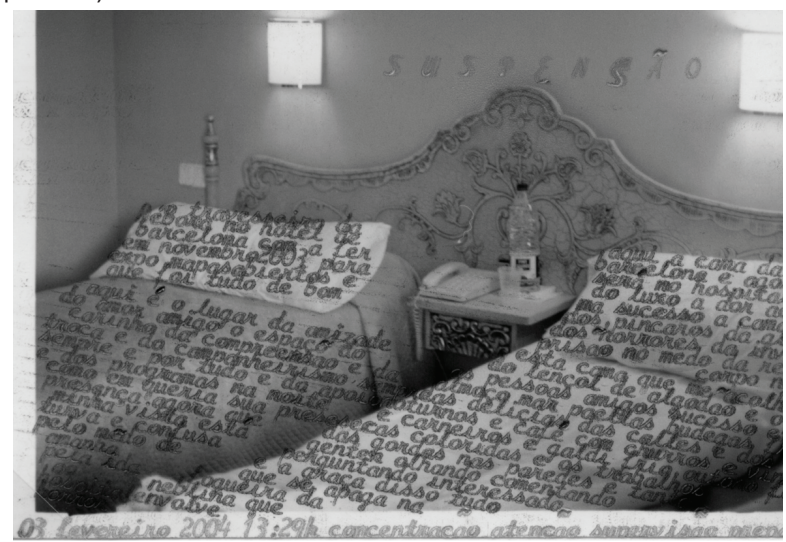

Figura 11 - "Suspensão" - Da série fotografias manipuladas Fonte: Arquivo Fernanda Magalhães.

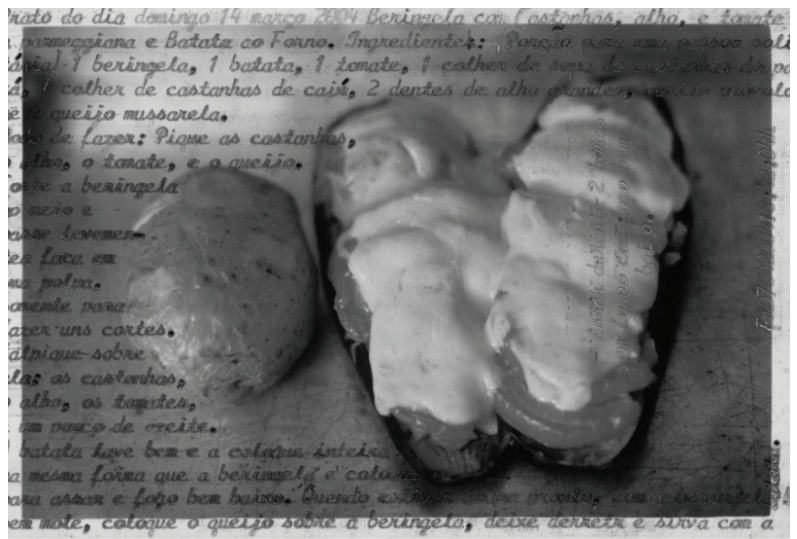

Figura 12 - "Prato do dia" - Da série fotografias manipuladas. Fonte: Arquivo Fernanda Magalhães. 


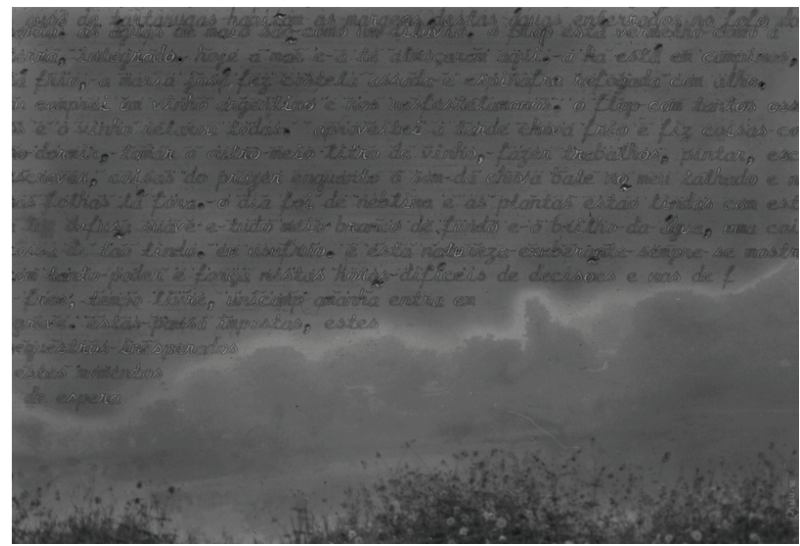

Figura 13 - "Ovos de tartaruga" - Da série fotografias manipuladas. Fonte: Arquivo Fernanda Magalhães.

A fotografia é a representação de sua morte, é a possibilidade de deixar sua marca, seu registro, é o atestado de sua existência aqui nesse mundo, pois leva à percepção do espaço do Eu, da identidade, da memória e da alteridade que se impregnam nas imagens de Fernanda Magalhães, além, é claro, de poder notar o corpo. O corpo é como um registro da memória, um ser evocador, pois "recordamos as fotografias para fazer presente o que ou quem está ausente", sendo que "a imagem fotográfica [...] carregará sempre o estigma de ser a realidade congelada no tempo" (ANDRADE, 2002, p.49 e 52).

Fernanda Magalhães transporta-nos para a oscilação entre aquilo que é real e o inconsciente, fruto proveniente da linguagem da fotografia. O trágico é testemunhado pela fotografia e esta concretiza a perenidade da existência, que é incerta e assustadora. Assim, o assustador pode ser possuído pela imagem fotográfica; a artista pode dominá-lo e transformá-lo em algo tangível, corriqueiro, sem se esquecer de que sua lembrança dói, sangra, escarra sofrimento e desespero.

Fernanda leva-nos a entender a fotografia como uma atitude de "participar da mortalidade, vulnerabilidade e mutabilidade de uma pessoa (ou objeto). Precisamente por lapidar e cristalizar determinado instante, toda fotografia testemunha a dissolução inexorável do tempo" (SONTAG, 1981. p.15). 
Toda a percepção da fotografia e sua experiência trágica carregam a artista para um ponto comum tanto em Nietzsche quanto em Kant?: a idéia de que a existência é um fardo pesado por demais que, ou carregamos pela arte, modificando, assim, o seu significado, valorando a vida, ou nos entregamos ao infortúnio do pessimismo, desintegrando-a.

Tanto em Fernanda, como em José Leonilson notamos a existência de uma arte trágica que os leva a uma nova atitude perante suas vidas. A experiência trágica vem pela doença. Ele, portador do vírus HIV, sofre da mesma acusação de transgressão que Fernanda Magalhães, pois é uma pessoa contaminada pela AIDS e, como tal, rejeitado pela sociedade. Contudo, ele faz um movimento contrário, tal qual Magalhães, rebela-se contra a doença numa atitude dionisíaca e, pela arte, consegue a superação das atrocidades.

Leonilson, considerado um dos maiores expoentes da arte brasileira, possui uma obra singular, ímpar, por meio da qual expõe suas vivências e experiências, sua transição, pois "o que há de grande no homem[...] é ser uma transição e um ocaso" (NIETZSCHE, s/d, p.31). Nesse pensamento, notamos que Leonilson, em sua obra, constrói seu trabalho de modo a explorar a transformação que ocorre, principalmente, após o acometimento da doença que o levará a óbito.

Vemos que suas obras querem "agradar e participar da transformação da vida de quem as vê, ou melhor, as vivencia" (CHIARELLI, 2006), pois propõem uma interlocução com o cotidiano das pessoas de modo a colocá-las em observação individual acerca de suas próprias vidas, questionando-se sobre o desdobramento das mesmas.

Segundo Nietzsche $(s / d, p .31)$, tal postura se faz necessária devido à necessidade de calor humano, de troca de experiências, mas, principalmente, pela existência do caos, pois ele acredita que "é preciso ter ainda caos dentro de si, para poder dar à luz a uma estrela dançante"; é exatamente isso que vemos em Leonilson. Tomado de caos e de transformações, isolado do mundo e dos outros, porque as pessoas tinham muito medo de aproximar-se dele devido à doença, o artista transforma tal deformação caótica de vida em expres- 
são, revelando "preocupações com a sociedade, a cidade, os relacionamentos" (PEDROSO, 2006), ativadas pela fragilidade imposta pela doença.

Em José Leonilson, presenciamos "uma arte que se abre [...] para a morte e que quer absorver a existência real na sua deficiência de existência finita" (GAGNEBIN, 1999, p.36), característica que se reflete em muitas de suas obras, numa tentativa de superar perante a morte e de enfrentamento da mesma com um olhar sensível, fragilizado, uma vitória sobre a finitude. A vida e a morte no trabalho de Leonilson são a mesma linha. Isto ocorre por uma análise de sua doença, mas, também, por uma análise autobiográfica de um sujeito sensível às atividades de si. Impossível seria conceber e estudar seus trabalhos sem compreender que a linha da vida está amalgamada profundamente em sua obra. Se ela não existe fisicamente, está implícita na subjetividade do ato artístico. Essa linha presente que apresenta um corpo é uma constante nas suas produções e são capazes de interconectar sua obra em diferentes tempos, demonstrando o elo entre vida e morte como fato primordial.

Da linha que costura as camisas siamesas na instalação feita na Capela do Morumbi em 1993, após sua morte, às linhas que asseguram a fratura dos pés da mesa em empty man, nota-se uma igualdade entre este homem vazio ou esvaziado com o homem ausente ou o corpo impossível da camisa especular. "Sem bombas, sem castelos na areia, sem bateria, tudo isto está em mim" (trecho bordado no próprio trabalho empty man). É assim que Leonilson nos dá o seu homem vazio e nos amarra junto dele aos pés fragilizados de uma mesa remendada como prova da finitude de seu corpo.

Do "sal.sangue.saliva" brotam a representação sexuada que se comprova pelo "amor" bordado contundentemente ao fato de estar "pronto". Uma prontidão de esvaziamento, um homem-tronco, esvaído de capacidades motoras, mas merguIhado em si prolongando-se ao outrem pela superfície de sua obra. Empty man remonta o sangue nas linhas vermelhas e a ausência da luz nas linhas negras. Um encontro entre a vida e a morte. Um duelo linear, onde ambas caminham juntas desde sempre, mas são confrontadas somente agora. Um momento 
onde as fronteiras são reconsideradas e a obra atinge uma supradimensão que elege o corpo como imperador de sua permanência. A permanência é contestada e o corpo então sofre a fragmentação a partir da cintura até os pés, as mãos são arrancadas e a cabeça também; sobre o tronco do coração, uma emoção tão explosiva que arranca as demarcações do corpo e assim vê-se a elaboração de um espaço que é o próprio corpo e a própria obra.

Numa leitura benjaminiana, podemos dizer que o trabalho de Leonilson é uma alegoria, pois, segundo Benjamin, "a alegoria se instala mais duravelmente onde o efêmero e o eterno coexistem mais intimamente" (BENJAMIN apud GAGNEBIN, 1999, p.37). É exatamente nessa linha tênue que a obra de Leonilson é deflagrada. Ele expõe, de modo especialmente sensivel seus duros questionamentos sobre sua própria finitude e sobre a efemeridade da vida, frente à qual não possui nenhuma garantia e nem mesmo domínio. Por isso, expressa-se pela arte, na tentativa de sublimar sua própria existencialidade, "pois quanto maior a significação, tanto maior a sujeição à morte porque é a morte que grava mais profundamente a tortuosa linha de demarcação entre a physis e a significação" (ibidem, p.44).

Por essa fatídica sujeição perante a morte, servem-nos as palavras de Ivo Mesquita, quando pondera que o trabalho de Leonilson reflete-se em "uma morte anunciada, pois assim é nos casos de enfermidades irreversíveis, e uma intensa busca de sentido para a travessia da vida" (ibidem).

Diante de Leonilson se está diante de outro paradoxo, pois ele vela a si mesmo, preenchendo o vazio dos últimos dias [...] com a elaboração de pequenos objetos e desenhos que vão adquirindo muito peso, o peso de uma existência que se esvai. Dessa invisibilidade que se instaura tanto pela abstração da morte, quanto pela sutileza do gesto gráfico que vai registrar não somente o visível, mas, principalmente, o vazio que estabelece uma única certeza: o fim da agonia com a morte (MESQUITA, Ivo apud BORBA, Maria, 2006.)

Por essa afirmação de Borba, podemos notar que se faz clara a teoria alegórica de Benjamin no que diz respeito à coexis- 
tência do eterno e do efêmero, como também, pelas palavras de Nietzsche, quando este nos coloca perante a questão existencial do ser como fruto finito, "criando imagens ao mesmo tempo efêmeras e duradouras que dizem a junção do temporal e do eterno" (ibidem, 2006).

Leonilson remete-nos a inúmeras dimensões que, talvez, só sejam possíveis de se alcançar mediante uma sensibilidade extrema, um enfrentamento com os temas propostos, uma inquietação autônoma derivada do ver/sentir a obra. O trabalho desse artista eleva sua condição humana a algo magicamente construído, no sentido de um confronto contínuo entre a efemeridade da vida e os desejos de eternidade do ser.

O fato é que, como nos declara Baudelaire, em seu artigo Do herosmo da vida moderna, "todos nós celebramos algum tipo de enterro" (BAUDELAIRE, 1998, p.25); e esse enterro celebrado por Leonilson é o de sua própria vida, de sua finitude: um reflexo de vida que fica e um corpo vivo que vai. $E$, nas palavras de Victor da Rosa (2006): "a morte, como um ponto final, a metáfora mais bonita. Aqui, não há mais diferenças".

\section{O que fica do corpo filotransmutado}

Antes da experiência de enfrentamento com a morte, antes de encarar o horror da vulnerabilidade humana, Fernanda Magalhães apreendia um olhar sobre a transgressão de um corpo gordo. Um corpo que não poderia existir, obrigado a modificar-se para ser aceito socialmente. Esse era o ponto central de sua poética. Sua única e exclusiva preocupação era, por meio da arte, escancarar esse corpo que a sociedade tanto odiava, devolvendo com a mesma intensidade, o sentimento arrebatador da violência que sentia em seu corpo, pelas imagens produzidas.

Quando do aparecimento da doença, todas essas singularidades se modificam, e seu corpo, então, por meio da arte e de sua atitude perante a vida, irá se tornar o seu maior instrumento de modificação. Pelo próprio corpo, que é dotado de linguagem, jamais se ausentado desta, ela metamorfoseia sua 
experiência estética, intensifica-a, transforma-a, filotransmutando sua poética. Daí a ligação que realizo entre o trabalho de Fernanda e o de José Leonilson.

Então, o que permanece desse corpo? Permanece a marca física. As cicatrizes físicas e emocionais, como memória do horror e da vitória, como testemunhos da experiência trágica, registradas no Ibum Cicatriz, se encontram nas fotografias da barriga da artista no dia anterior a cirurgia e sua barriga após a mesma. Tais fotografias são recortadas e manipuladas. Fica a obra como expressão do âmago, como apologia à aparência da vida, como atestado de que Sileno não seria o cerne, mas os véus de Maia e o poder extático de Dionísio, exaltados pela aparência de Apolo.

\section{Notas}

1. Nietzsche apresenta-nos a sabedoria do semi-deus Sileno, o qual demonstra que a única possibilidade de vida é a própria morte. Dotado de um pessimismo ímpar, Sileno é a representação da companheira morte, de finitude inexorável.

2.Este conceito é explicitado no decorrer do texto.

3. Foucault em Os Anormais estabelece exemplos dessas diferentes atitudes tomadas pelas sociedades. Demonstra que por muito tempo a lepra foi motivo de rejeição, isto é, a doença foi motivo de rejeição e que já na Idade Clássica, desde o séc. XVIII mais precisamente, passou-se a existir uma política de inclusão sobre a Peste e, portanto, capaz de gerar uma organização disciplinar alcançando a normatizao social, estabelecendo um conhecimento acerca do indivíduo doente e do indivíduo sadio. Não mais esse indivíduo era isolado, rejeitado, era incluso na sociedade, mas era tido como doente, anormal, pois se encontrava em estado não "normal".

4. Mafesolli em O tempo das tribos: o declnio do individualismo nas sociedades de massa. 3 ed. Rio de Janeiro: Forense Universitrio. 2000, fala-nos sobre a existencialidade do eu e a apreensão do que ele chama de vitalismo, uma potência capaz de nos tornar vivos, de afirmarmos a vida e querer viver, dando continuidade à nossa experimentação cotidiana. $\mathrm{Na}$ página 46 escreve [...] a apreensão do vitalismo: pelo fato de que nele, a vida se faz muito mais presente que o nada ao invés da separação, da alienação e da atitude crítica que a exprimem, importa agora analisar "a afirmação" da vida, o querer viver societal que mesmo de maneira relativista serve de suporte à vida cotidiana "vista de perto".

5. Nietzsche elabora um pensamento acerca da arte e, para isso, utiliza-se da tragédia Ática, ocorrida anteriormente à tragédia clássica. Apolo seria o Deus da aparência. Preocupado em aproximar-se de sua finitude, Apolo apresenta, contra o pessimismo de Sileno, os Véus de Maia, encobrindo então a vida de aparência e de ilusão. Estabelece a idéia de puro prazer em se estar vivo. Já Dionísio encara a finitude de outra maneira, ele vê que tudo que está na aparência faz parte da vida e, portanto, deve assimilar-se à finitude do ser, mas para que essa assimilação seja transcendente e, portanto, válida, o sujeito deverá experimentar o dionisíaco, o êxtase, a embriaguez dos sentimentos e da própria existência. 
6. Em entrevista sobre o seu trabalho, concedida especificamente para a elaboração deste texto, Fernanda Magalhães demonstra uma argumentação que a faz preocupada em alcançar somente o dia seguinte, que para ela, naquele momento de vida este significava o único lugar possível de sobrevivência, então, alcançar esse dia seguinte, esse futuro muito próximo, seria a sua continuidade e, portanto, o lugar onde ela conseguiria se fortalecer mais ainda pela própria tragédia de seu corpo.

7. Tais pensamentos tornam-se claros para Kant em seu ensaio intitulado A paz perpétua e outros opúsculos, onde este estabelece uma discussão acerca das verdades dos homens e de suas disposições naturais. Em Nietzsche, a idéia do pessimismo está presente desde a arte apolínea, mas se concretiza com o pensamento niilista do ser.

\section{Referências}

ALVES, Rubem A. A morte como conselheira. In: CASSORLA, Roosevelt M. S. (org.). Da morte estudos brasileiros.2ed. Campinas: Papirus, 1998. pp.1215.

ANDRADE, Rosane de. Fotografia e antropologia: olhares fora-dentro. São Paulo: EDUC. 2002.

ARIES, Philipe. Sobre a historia da morte no Ocidente desde a Idade Mdia. Lisboa: Teorema, 1989.

BAUDELAIRE, Charles. Do herosmo da vida moderna. In: COELHO, Teixeira (org). A modernidnade de Baudelaire. Rio de Janeiro: Paz e Terra, 1998. pp.23-27.

CANGUILHEN, Georges. Novas reflexes referentes sobre o normal e o patolgico. In: O normal e o patológico. Rio de Janeiro: Forense Universitária, 1995. pp.205-261.

CHIARELLI, Tadeu. Colocando dobradias na arte contempornea. Disponível em: http://www2.uol.com.br/leonilson. Acesso dia 14/11/06.

DANTAS, Marta. A obra de passagem. In: Arthur Bispo do Rosário: a estética do delírio. Tese de Doutorado em Sociologia, UNESP/UNIL. São Paulo - SP, 2003.

DELEUZE, Gilles e GUATARRI, Félix. Rizoma. In: Mil Platôs: capitalismo e esquizofrenia. Vol. 1. Rio deJaneiro: Ed. 34, 1995.

FOUCAULT, Michel . As dimenses psicolgicas da doena. In: Doença mental e psicologia. Rio de Janeiro: Tempo Brasileiro, 1994.

Os anormais. Sao Paulo: Martins Fontes, 2001.

FRAIZE-PEREIRA, Joao A. A fotografia como percepao: perspectivismo, transcendência e dor. In: Arte, Dor. Cotia/Sao Paulo: Ateliê editorial, 2005.

GAGNEBIN, Jean-Marie. Alegoria, morte, modernidade In: História e narração em Walter Benjamin. São Paulo: Perspectiva, 1999. pp.31-53. 
GATTI, Fábio L. O. Fernanda Magalhes sobre o Projeto S.O.S. Londrina: própria, 2006a. 1 cassete son. (25 min.): estéreo.

. Fernanda Magalhes sobre Corpo Re-Construo AçãoRitualPerformance. Londrina: própria, 2006b. 1 cassete son. (30min): estereo.

KANT, Immanuel. A paz perptua e outros opsculos. Rio de Janeiro: edições 70. 1995.

LYOTARD, Jean-François. O ps-moderno. Rio de Janeiro: José Olympio, 1986.

MACHADO, Roberto. Nietzsche e a verdade. Graal, 1999.

MAFESOLLI, Michel. O tempo das tribos: o declínio do individualismo nas sociedades de massa. 3 ed. Rio de Janeiro: Forense Universitário. 2000.

MAGALHÃES, Fernanda. Corpo-Reconstruo Ação, Ritual, Performance. In: GARCIA, Wilton (org.). Corpo e Subjetividade - estudos contemporâneos. Saõ Paulo: Factash Ed., 2006. pp. 76-85.

MEDEIROS, Margarida. Fotografia e narcisismo: o auto-retrato contemporâneo. Lisboa: assírio e Alvim. 2000.

MEICHES, Mauro P. Uma aproximao ao Pathos Trgico. In: A travessia do trágico em analise. São Paulo: Casa do Psicólogo, 2000.

MELIM, Regina (2003). InCORPOrAES: agenciamentos do corpo no espaço relacional. Tese de Doutorado. Programa de Comunicação e Semiótica - Artes. PUC/SP.

MORIN, Edgard. O homem e a morte. Trad.: Cleone Augusto Rodrigues. Rio de Janeiro: Imago Ed., 1997.

NIETZSCHE, Friedrich W. Assim falou Zaratrusta. 9a Ed. Rio de Janeiro: Bertrana Brasil. s/d.

PEDROSO, Néri. Conversa na primeira pessoa do plural - entrevista com Ricardo Resende. Disponível em: http://www.netprocesso.art.br. Acesso dia 17/11/06.

PROJETO LEONILSON. Disponível em <http:www2.uol.com.br/leonilson>. Acesso dia 23/11/2006.

RODRIGUES, J. C. O tabu do corpo. Rio de Janeiro: Dois Pontos, 1986.

RODRIGUES, L. G. Nietzsche e os gregos. Arte e mal-estar na cultura. São Paulo: Anna blume, 1998.

ROSA, Victor da. Distncias entre dois pontos (anotações para Leonilson). Disponível em: http://museuvictormeirelles.org.br/umpontoeoutro/nuemro1/victordarosa.htm. Acesso dia 17/11/06.

SONTAG, Susan. Ensaios sobre fotografia. Editora Arbor. Rio de Janeiro, 1981.

VICTORIA, Ceres G. As imagens do corpo: representações do aparelho 
O Corpo de Fernanda Magalhães perante a experiência trágica

reprodutor feminino e reapropriações dos modelos médicos. In: LEAL, Ondina Fachel (org). Corpo e significado. Porto Alegre: Ed. Universidade/ UFRGS, 2001.

\section{Fábio Luiz Oliveira Gatti}

Mestre em Artes Visuais pela EBA-UFBA. Especialista em Fotografia e em História e Teorias da Arte - Modernidade e Pós-modernidade, ambas pela Universidade Estadual de Londrina. Graduado em Desenho Industrial pela Universidade Norte do Paraná em Londrina. <www.flickr.com/photos/fabiogatti/ www.fotolog.com/fgatti>.

E-mail:gatti_f@yahoo.com.br 